\title{
Profile of autopsy cases in central level hospital of Nepal. A retrospective study of two years
}

\author{
Madan Prasad Baral \\ Assistant Professor Department of Forensic Medicine Pokhara Academy of Health Sciences (PAHS) Western Regional \\ Hospital, Pokhara, Nepal
}

Background: Autopsy is a systemic scientific examination of dead body by the help of which information about the cause of death can be obtained in unnatural death cases. Various countries have to follow their own law to perform an autopsy. Aims and Objectives: This study aims to analyze the pattern of autopsy cases with manner and various cause of death, which was conducted in central level hospital. Materials and Methods: It is a retrospective type record based study conducted in two years period at central level hospital of Nepal in 775 corpse. Results: Out of 775 cases of autopsy, 465 males and 310 females which accounts $60 \%$ of male and $40 \%$ of female cases.In context of age group the highest number of cases came for autopsy is $21-30$ years of age group which accounts $39.35 \%$ of total cases followed by $31-40$ years of age group and accounts $31.61 \%$ of total cases. Suicidal death cases are the highest number of cases presented $59.09 \%$ for autopsy. This is followed by accidental deaths of $27.48 \%$ and thenundetermined $9.29 \%$ and lastly homicidal $4.12 \%$. Regarding the cause of death blunt injury cases are highly presented with $44.54 \%$ and the firearm injury cases are presented very less with only $0.25 \%$ in total 775 cases. Conclusion: In the current study it can be concluded that the Medico legal autopsy was performed in 775 corpse in a period of 2 years at central level hospital where the Male cases are predominated over Female with presence of the highest number of cases in an age group of 21-30 years. Suicidal manner of death cases are highest in number with the

Access this article online Website:

http://nepjol.info/index.php/AJMS DOI: $10.3126 /$ ajms.v11i3.27560

E-ISSN: 2091-0576

P-ISSN: 2467-9100

Copyright (c) 2020 Asian Journal of Medical Sciences

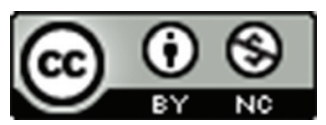

This work is licensed under a Creative Commons Attribution-NonCommercial 4.0 International License. leading cause of death as Blunt injury.

Key words: Autopsy; Medico legal cases; Central level Hospital Nepal

\section{INTRODUCTION}

The term 'Autopsy' instigates from ancient 'Autopsia' which is derived from 'Autos' i.e., 'Oneself' and 'Opsis' i.e., 'to see for oneself'. An autopsy is regularly done in cases of sudden death where a doctor is unable to give a death certificate or when death is believed due to an unnatural cause. ${ }^{1}$ Autopsy refers to the systematic examination of a dead person for medical, legal and/or scientific purposes. There are three types: i. Academic: Dissection of dead body carried by students of anatomy. ii. Pathological, clinical or hospital: Conducted by pathologists to diagnose the cause of death or to approve a diagnosis. Physicians cannot order these autopsies without the consent signed by the next of kin. iii. Medico-legal or forensic: Type of scientific examination of a dead body carried out under the laws of the Nation for the protection of rights of citizens in cases of sudden, suspicious, obscure, unnatural, litigious or criminal type of deaths. The basic purpose of this autopsy is to establish the cause and manner of death. ${ }^{2}$ In Nepal to do an autopsy in any corpse a requisition letter from police is required as per latest law of Nepal. ${ }^{3}$ The main objective of this study is to analyze the pattern of autopsy cases with manner and various cause of death, which was conducted in tertiary hospital of Nepal.

\section{MATERIALS AND METHODS}

It is a retrospective type of study which is based on medical records of autopsy cases conducted in Western 
Regional Hospital of Pokhara Academy of Health Sciences, Gandaki Province, Nepal. Thorough study of Autopsy cases conducted intwo years of time period from B.S 2073 Poush.to B.S. 2075 Poush(January $1^{\text {st }} 2017$ A.D. to January $1^{\text {st }} 2019$ A.D.) included in the current study. Necessary data from total 775 cases $(n=775)$ collected, analyzed and presented in the study after ethical clearance from institution. Only the medico legal autopsies conducted by forensic expert were included and the autopsy cases conducted by other than forensic experts were excluded.

\section{RESULTS}

In a period of two years, 775 autopsies were conducted. All cases were sent by police offices of Gandaki Province after preliminary examination of dead body and proper inquest. Out of 775 cases of autopsies conducted, 465 subjects were males $(60 \%)$ and remaining 310 were females (40\%) which is shown in Table 1.

Likewise in context of age group the highest number of cases came for autopsy is 21-30 years of age group which accounts $39.35 \%$ of total cases followed by $31-40$ years of age group and accounts $31.61 \%$ of total cases. The least age group attended for autopsy is $81-90$ years which is only one and accounts $0.12 \%$ of total cases and just behind it followed by age group of 71-80 years which accounts only $0.51 \%$ of total cases depicted in Table 2 .

In perspective of manner of death, the highest number of cases presented for autopsy was suicidal death cases which were 458 out of total 775 cases comprising $59.09 \%$. This was followed by accidental death cases which were 213 out of 775. Third common case was homicidal comprising of $4.12 \%$ and the rest of the cases were undetermined manner comprising of 72 cases $(9.29 \%)$ which is well illustrated in Table 3.

Regarding the cause of death highest number of cases presented for autopsy was 260 cases out of 775 cases $(33.54 \%)$ was due to Blunt injury. This is immediately followed by death due to hanging which were $127(16.38 \%)$ in number.The third most cause of death was due to disease resulting in $14.06 \%$ of cases. The least was of gunshot injury which comprised of only two cases of the total of 775 cases it is mentioned in Table 4.

\section{DISCUSSION}

\section{Gender-wise analysis}

In this study the review of cases of autopsy done for the past two years revealed that the female autopsy cases were dominated by male cases. This finding is consistent

\begin{tabular}{lcc}
\multicolumn{4}{l}{ Table 1: Sex wise distribution of cases } \\
\hline Male & Female & Total=n \\
\hline $465(60 \%)$ & $320(40 \%)$ & $775(100 \%)$ \\
\hline
\end{tabular}

\begin{tabular}{lc}
\multicolumn{3}{l}{ Table 2: Age wise distribution of cases } \\
\hline Age Group in year & No. of Cases \\
\hline $0-10$ & $35(4.51 \%)$ \\
$11-20$ & $67(8.64 \%)$ \\
$21-30$ & $305(39.35 \%)$ \\
$31-40$ & $245(31.61 \%)$ \\
$41-50$ & $58(7.48 \%)$ \\
$51-60$ & $42(5.41 \%)$ \\
$61-70$ & $18(2.32 \%)$ \\
$71-80$ & $04(0.51 \%)$ \\
$81-90$ & $01(0.12 \%)$ \\
\hline
\end{tabular}

\section{Table 3: Manner wise distribution of cases}

\begin{tabular}{lccc}
\hline Suicidal & Accidental & Homicidal & Undetermined \\
\hline $458(59.09 \%)$ & $213(27.48 \%)$ & $32(4.12 \%)$ & $72(9.29 \%)$ \\
\hline
\end{tabular}

\begin{tabular}{lc}
$\begin{array}{l}\text { Table 4: Distribution of cases as per cause of } \\
\text { death }\end{array}$ \\
\hline Cause of death & Number of cases \\
\hline Blunt injury & $260(33.54 \%)$ \\
Sharp injury & $12(1.54 \%)$ \\
Electric current injury & $7(0.90 \%)$ \\
Firearm (gunshot) injury & $2(0.25 \%)$ \\
Burn injury & $14(1.80 \%)$ \\
Hanging & $127(16.38 \%)$ \\
Drowning & $83(10.70 \%)$ \\
Poisoning & $89(11.48 \%)$ \\
Disease condition & $109(14.06 \%)$ \\
Undetermined & $72(9.29 \%)$ \\
\hline
\end{tabular}

with the report of Ngbeaetal ${ }^{4}$ conducted in Nigeria. Study conducted elsewhere also found that the medico legal cases presented in tertiary care hospital were outnumbered by males ${ }^{5}$ and their report is consistent with the findings of the current study. Yadav et al conducted a study in Dharan Nepal regarding the profile of medico legal cases coming to emergency, also reported higher cases of male (62.7\%) compared to female $(37.3 \%)$ respectively. ${ }^{6}$ Similarly a study conducted by Dileep Kumar R et al in Kerala, India also observed similar findings as observed in the current study. ${ }^{7}$ Yet another study conducted in South Kerala also had a similar findings were males cases $(71.2 \%)$ outnumbered the females. ${ }^{8}$

\section{Age-wise analysis}

About the age group distribution of medico legal cases Tanuja R. Brahmankar, Sachin K. Sharma found Maximum assault cases were from the age group of 2130 years $(33.1 \%)$ followed by $31-40$ years $(28.4 \%)$ which is similar with the current study in which author found in age group of 
21-30 years which is followed by $31-40$ years. ${ }^{5}$ Dr. Manju. L and Dr. Nazeema Beevi's study showed the distribution of cases according to age is highest proportion falls in the age group 20-30 years $(29.7 \%)$ followed by $30-40$ years $(19.3 \%){ }^{8}$ which is alike to current study as per age group. Dileep Kumar $\mathrm{R}$ et al found shows that maximum number of cases were belonged to the age group of 21-30 years (53 cases) followed by $31-40$ years ( 35 cases). ${ }^{7}$ which is almost comparable and consistent to current study as current one is the study about autopsy which also comes under medico legal cases.

Trangadia et al did a retrospective study in a tertiary care hospital of Gujrat India and found that male cases were predominated over female cases which were 5967 (72.77\%) and $2232(27.23 \%)$ respectively. The maximum numbers of cases were in the age group 21-30 years, $2632(32.10 \%)^{9}$ this is quiet similar with current study conducted by author in Nepal.

\section{Manner-wise analysis}

About the manner of death, study conducted in Sri Lanka by Kitulwatte e al reported that $40 \%$ deaths were accidental while $32 \%$ were suicides, $24 \%$ homicides and $4 \%$ other deaths due to pregnancy and parturition-related issues. ${ }^{10}$ Likewise Rajoo's study mentioned that manner of $63.22 \%$ deaths are accidental followed by $24.83 \%$ suicidal and then $8.06 \%$ undetermined and last is homicidal with $3.88 \% .{ }^{11}$ Similarly CK Pawar et al mentioned in their study that accidental death is $57 \%$, followed by $30 \%$ suicidal, $11 \%$ homicidal and $2 \%$ are Undetermined. ${ }^{12}$ All of these above mentionedstudy are contrary with current studyconducted by author in Nepal as suicidal cases are maximum in number in current study. Thounaojam Meera et al had found maximum number of cases are of Accidental $72.50 \%$ followed by homicidal $23.75 \%$ and then suicidal $3.75 \%$ as this study was focused only on nature of female death cases. ${ }^{13}$

\section{Cause of death wise analysis}

Romana Malik et al depict in their study that cause of death are $40 \%$ RTA (Road Traffic Accident), 31\% blunt injury, $19 \%$ sharp injury, $2 \%$ sexual assault, $4 \%$ poisoning and $4 \%$ firearm cases. ${ }^{14}$ Study conducted in Ethopia by Solano showed the cause of deaths in forensic science are due to strangulation $(7.5 \%)$, suffocation $(0.8 \%)$ others $(0.5 \%)$, hanging $(88 \%)$, poisoning $(10 \%)$, bullet $(0.7 \%)$, drowning $(8.5 \%)$, electric current injury, burn $(0.8 \%) .{ }^{15}$ This report is comparatively different from the reports of the current study as cause of death by Blunt injury cases were higher in number which is immediately followed by hanging and then other causes. Marri et al mentioned that the cause of death in their one year study is Hanging $37.5 \%$, Drowning $12.5 \%$, burn $0.93 \%$, electrocution $4.67 \%$, bullet $1.87 \%,{ }^{16}$ which is quiet similar to the reports of the current study in cases of causes of death due to burn and drowning. Study reported by Chughtai et al observed that the causes of death in their institution were due to blunt injury $14.06 \%$, sharp force $6.25 \%$, drowning $4.68 \%$, firearm $51.56 \%$ in one year study ${ }^{17}$ which is almost consistent with the current study. Aziz et al reported $58 \%$ of deaths were due to blunt force ${ }^{18}$ is consistent with current study except death due to firearm injury. Bansude et al in their study observed cause of death by trauma is $38.09 \%$, burn injury $26.73 \%$, Asphyxia $9.8 \%$ and poisoning was $21.21 \%,{ }^{19}$ where the death due to trauma is consistent with the current study. Sharma et al found death due to burn injury as a cause of death was $7 \%$, hanging is $5 \%,{ }^{20}$ which differs from the current study as death due to hanging cases are higher in number than those due to injury cases.

\section{Limitations of the study}

The current study is a finding from the follow up for two years duration. Furthermore study is required to be conducted in a long term follow up to get the better data. It is limited to only one central Hospital of Nepal.

\section{ACKNOWLEDGEMENTS}

The author acknowledges Pokhara Academy of Health Sciences (PAHS), Western Regional Hospital which provided a platform for this study. The author is indebted to MedicalRecord Section and entire team of Forensic Medicine division including staffs and police personnel of the hospital.

\section{REFERENCES}

1. Vij K. Text book of forensic medicine and toxicology, Fourth ed. 2008:pp 24-25.

2. Biswas G. Review of Forensic Medicine and Toxicology, Third Ed. Jaypee Brothers Medical Publishers the Health Science publishers: 2015, pp 98.

3. National Criminal Procedure (code) Act 2017, Chapter2, number 8(a).

4. Joseph A. Ngbea RA, Vhritherhire BA, Ojo IO, Akpor T, Nyaga BA, et al. Medico legal autopsies in Benue state university teaching hospital, Makurdi North Central Nigeria, A5 year review. International Journal of Healthcare Sciences 2017-2018; 5(2):641-645.

5. Brahmankar TR and Sharma SK. A record based study of frequency and pattern of medico-legal cases reported at a tertiary care hospital in Miraj. International Journal of Community Medicine and Public Health 2017; 4(4):1348-1351.

https://doi.org/10.18203/2394-6040.ijcmph20171374

6. Yadav AK, Shah B, Budhathoki SS, Chaudhur, S, Aryal BD and Malla GB. Profile of Medico-legal Cases Coming to Emergency ward of B. P. Koirala Institute of Health Sciences. JBPKIHS 2018; 1(2):50-56.

https://doi.org/10.3126/jbpkihs.v1i2.22078 
7. Dileep Kumar R, Siddaramanna TC, Parate SV and Hemanthraj MN. Retrospective Study of Profile of Medico-legal Cases in Tumkur Region, Karnataka. International Journal of Biomedical and Advance Research 2015; 6(04): 339-340.

8. Manju L and Nazeema Beevi PA. Study on Medico Legal Cases Attended in a Tertiary Care Hospital in South Kerala. International Journal of Health Sciences \& Research 2018; 8(11):257-260.

9. Trangadia MM, Mehta RA, Rada NH and Gupta BD. Profile of medico-legal cases in tertiary care hospital in Jamnagar, Gujarat: Retrospective study of one year. Journal of Research in Medical and Dental Science 2014; 2(4):57-62.

https://doi.org/10.5455/jrmds.20142411

10. Kitulwatte IDG, Edirisinghe PAS, Pratheepa Mendis HKNL, Wijesinghe PR, Fernando A and Rishani MAA. Study on the pattern of unnatural deaths of women brought for medico legal autopsy. Sri Lanka Journal of Forensic Medicine, Science \& Law 2017; 8(1):13-22.

https://doi.org/10.4038/sljfmsl.v8i1.7789

11. Dere RC and Rajoo KM. Study of Unnatural Deaths in Females a Medicolegal Study at Rural Medical College Loni. J Indian Acad Forensic Med 2011; 33(3):211-213.

12. Pawar CK, Bhullar DS, Oberoi SS and Aggarwal KK. Profile of Unnatural Deaths in Females a Retrospective Study. J Indian Acad Forensic Med 2014; 36(2):122-124.

13. Thounaojam M, Nandeibam P, Fimate L, Maring SK and Sangma M. Spectrum of unnatural female deaths in Manipur: A postmortem study. Journal of Medical Society 2015; 29(2):88- 91. https://doi.org/10.4103/0972-4958.163197

14. Malik R, Iffat A, Rashid F and Abbas M. An analysis of 3105 Medico Legal Cases at Tertiary Care Hospital, Rawalpindi. Pak J Med Sci 2017; 33(4):926-930.

https://doi.org/10.12669/pjms.334.11696

15. Solano EE, Mayedo YO and Seyoumk M. A One-year Retrospective Study on the Pattern of Death Found at Autopsy at Forensic Pathology Department, Menelik II Hospital in Addis Ababa, Ethiopia. East \& Central African Journal of Surgery 2017; 22 (1):98-106.

https://doi.org/10.4314/ecajs.v22i1.13

16. Marri MZ, Zahid Bahir M, Arif M and Maqsood M. Analysis of Medico legal Deaths in Sandeman Civil Hospital Quetta, Balochistan. JFMC 2013; 7(2):13-18.

17. Chughtai B, Iqbal $M$ and Afraz N. Study of Medico-Legal Autopsies at Tehsil Level. Journal of Rawalpindi Medical College (JRMC) 2013; 17(2):275-276.

18. Aziz F, Azhar T and Baluch NA. Manners and Modalities of Unnatural Deaths in Multan. PJMHS 2017; 11(4):1472-1474.

19. Bansude ME, Kachare RV, Dode CR and Kumre VM. Trends of unnatural Deaths in Latur District of Maharashtra. Journal of Forensic Medicine, Science and Law 2012; 21(6):7.

20. Sharma DK, Meena PR, Punia RK and Pathak D. Comparative trends of accidental to intentional mortalities over aoneyear period at a tertiary care centre. International Journal of Research in Medical Sciences 2018; 6(5):1574-1578. https://doi.org/10.18203/2320-6012.ijrms20181453

\footnotetext{
Authors Contribution:

MPB-All including conceptualized study, literature search, statistically analyzed and interpreted, prepared first draft of manuscript and critical revision of the manuscript,Concept and design of the study, reviewed the literature, manuscript preparation, critical revision of the manuscript; statistically analyzed and interpreted; revision of manuscript and review of study.

Work attributed to:

Department of Forensic Medicine, Pokhara Academy of health Sciences (PAHS), Western Regional Hospital (WRH).Gandaki Province, Pokhara, Nepal.

Orcid ID:

Dr. Madan Prasad Baral - (1) http://orcid.org/0000-0001-6182-2778

Source of Support: None, Conflicts of Interest: None.
} 